\title{
SYMBIOSIS BETWEEN SOCIAL SPIDERS AND YEAST: THE ROLE IN PREY ATTRACTION
}

\author{
By William James Tietjen ${ }^{1}$, L. Rao Ayyagari ${ }^{1}$ \\ AND GEORGE W. UETZ ${ }^{2}$
}

\section{INTRODUCTION}

A number of predatory animals use deception, including odors, signals, and bait-like body appendages or objects to lure prey (Alcock, 1984). Several spider species are known to emit chemical odors that mimic the sex attractants of certain noctuid or saturniid moths as a means of luring males to be captured (Tietjen and Rovner, 1982). Here we provide evidence that the social spider species, Mallos gregalis, uses a scented "bait" to attract prey. Our results indicate that this odor is produced by yeasts growing on the carcasses of previously fed-upon flies which these spiders incorporated into their webs.

Mallos gregalis is a social spider from Mexico which lives in huge colonies that may cover whole tree branches with webbing. Up to 20,000 individuals of both sexes and various stadia may occupy these extended colonies. Predation, feeding and nest construction are communal, with little or no cannibalism occurring among group members (Burgess, 1978; Tietjen, 1986).

Early records of $M$. gregalis indicated that the Indians of Michoacan used the spider colonies as natural fly traps. These reports also suggested that the nests attracted flies and prompted the importation of $M$. gregalis to France in the early part of this century as a potential biocontrol agent (Diguet, 1909a; 1909b). Recent field observations on $M$. gregalis have noted that swarms of muscoid flies sometimes surround the nest, although no attractants (such as animal carcasses) could be found in the immediate area (Burgess, 1979; Uetz pers. obs.). These observations, and the apparent specialization of Mallos on dipteran prey have raised questions about the attractiveness of M. gregalis nests to flies (Jackson, 1977; 1980).

'Department of Biology, Lindenwood College, Saint Charles, MO 63301. ${ }^{2}$ University of Cincinnati, Biological Sciences, Cincinnati, OH 45221-006 Manuscript received by the editor March 25, 1987. 
Unlike most other social spiders, $M$. gregalis do not remove prey remains from their web, but rather incorporate these debris into the nest matrix (Tietjen, 1986). It seemed possible that this apparent untidiness might attract more prey, so we examined colonies in the field and laboratory for evidence of prey attraction.

Both field-collected nests and webs constructed by spiders in the laboratory had a sweet, yeast-like odor. A change from this usual sweet scent to an odor of ammonia often precedes population crashes or mass emigration, suggesting changes in web's microflora. The presence of microbiota in Mallos nests is likely, given their habit of incorporating prey remains into the web and the high-humidity conditions within the web (Tietjen, 1986). Mallos also do not completely consume their prey, which undoubtedly provides a rich medium for microbial growth (Burgess, 1978; Uetz, 1983). If these social spider webs actually do attract prey, this may be an important factor in maintaining group cohesion and/or allowing a relatively high population density in a marginal (seasonal subhumid or xeric) habitat.

\section{MeTHODS}

\section{Field analyses}

Mallos gregalis nests were collected from several sites including Guadalajara, Guanajuato, Mexico City and Tuxpan (Mexico), among the branches of Mexican Blue Oak (Quercus oblongifolia). A subsection of a typical colony $(20 \times 8 \times 10 \mathrm{~cm})$ was torn apart and the flies contained therein counted and identified. Inside the webbing, carcasses of 129 insects were found: 115 muscoid Diptera (Calliphoridae, Calliphora sp., 76 individuals; Sarcophagidae, Sarcophaga sp., 18 individuals; Muscidae, sp. unknown, 21 individuals), 9 Hymenoptera, 4 Coleoptera, and 1 Hemiptera. The large quantities of fly carcasses suggested the presence of an animal carcass or garbage pile nearby and more than a dozen flies hovered about the colonies when they were collected, but a systematic search of the surrounding area indicated there were no other potential fly attractants nearby.

\section{Culture methods for microbiota}

Adult $M$. domestica were reared in the laboratory and fed to colonies of $M$. gregalis. The fly carcasses (with a minimal amount of 
attached silk) were removed at random from the nests and assayed to determine the types of microflora associated with the flies. Flies were homogenated in $5.0 \mathrm{ml}$ of triptose soy broth (TSB) and then transferred to $50 \mathrm{ml}$ flasks and incubated at $22^{\circ} \mathrm{C}$ in a shaker bath for $24 \mathrm{hr}$. The broth was then transferred to agar plates and incubated for $48 \mathrm{hr}$ at $35^{\circ} \mathrm{C}$. Among the three types of agar media, triptose soy agar (TSA) supported mainly bacterial growth while Peptone-Yeast extract-Glucose (PYG), and Saboraud supported mainly fungal growth. Prey from the field-collected nests were similarly treated and plated on Nutrient agar and Saboraud.

Several other potential sources of microbiota were similarly assayed: non-fed-upon flies, adult female $M$. gregalis, web silk alone, stock fly food (powdered milk and sucrose, 3:1), soiled fly food removed from the fly rearing cages, and flies that other species of spiders had fed upon. Members of the following families were tested, as available: Agelendidae, Lycosidae, Linyphiidae, Salticidae, and Theridiidae. These tests were run using Saboraud agar. Web silk alone was obtained by establishing a colony in a Petri dish ( $\mathrm{N}=20$ adult female $M$. gregalis), not feeding the spiders while they deposited silk, and then collecting the nest material a week later.

\section{Behavioral assays}

Groups of 15 flies were presented with paired stimuli to assess attraction to nest odors and/or associated microbiota. Flies were removed from access to food for 2-3 hr prior to testing. They were then introduced into a plexiglas test arena painted flat black on the interior $(321 \times 32 \mathrm{w} \times 20 \mathrm{~h} \mathrm{~cm})$ and, following an acclimation period of $20 \mathrm{~min}$, were presented with paired odor sources (the control and a single experimental odor). Odor sources were contained in Petri dishes $(9.3 \mathrm{~cm}$ dia) covered with clean white cotton cloth. The position of the control and experimental odors (yeast cultures from fed-upon flies, mixed microbiota from non-fed-upon flies, clean silk or Mallos nest material with prey) was randomized for each run. Empty petri dishes were used as controls when nest silk was presented as the experimental stimulus, sterile media was used as a control when cultures were presented as experimental stimuli. Following introduction of the stimuli, flies were allowed an additional 5 -min for acclimation followed by the 5-min recording period. The number of contacts with the upper cotton surface of the Petri dishes was scored as an index of attraction ( $\mathrm{N}=20$ for all series). 


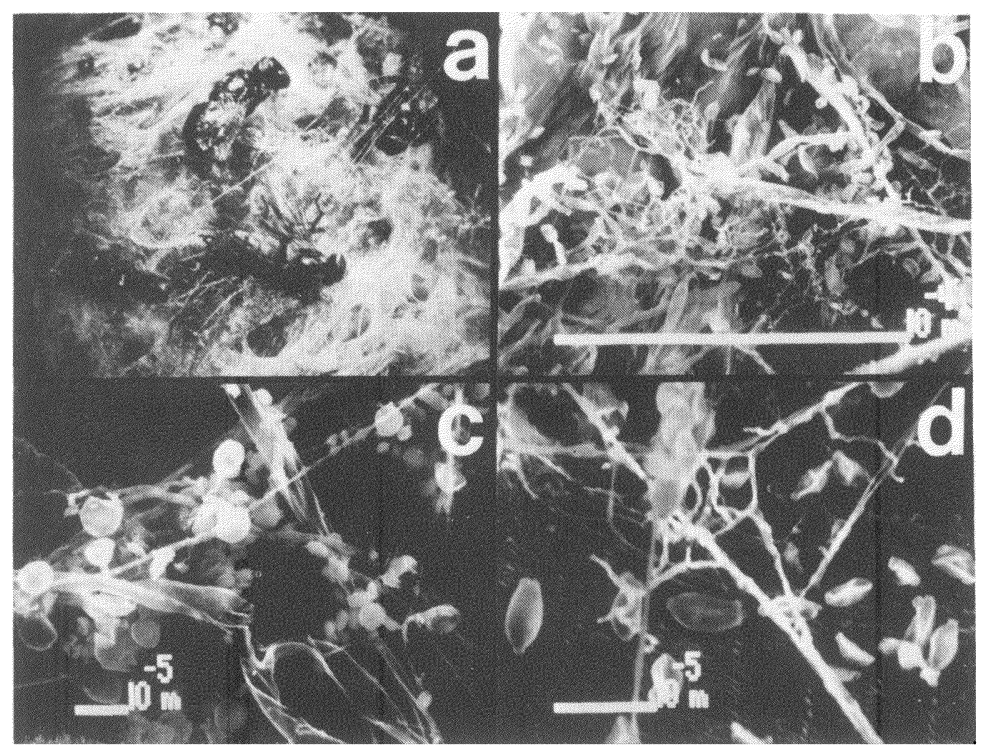

Fig. 1. a. Interior of Mallos colony, showing fly carcasses; b. SEM photo of microbiota community found on the interior abdomen of a fly from a Mallos colony; c. SEM photo of yeasts; d. SEM photos of individual collapsed yeast cells.

\section{RESULTS}

If spiders are not fed while building their nests in the laboratory, the webs do not acquire the sweet odor until prey (Musca domestica) are provided. Removal of fly carcasses is associated with a loss of this odor, suggesting that microbiota associated with the flies or feeding process of the spiders might be responsible for the scent of Mallos nests. Microscopic examination of fly carcasses reveals the presence of numerous hyphae, sporulating bodies, and budding yeasts (Fig 1).

Flies that had been killed and fed upon by $M$. gregalis had an altered microbiota when compared to most of the controls (Table 1). The odor of the yeast cultures (PYG plates) was very similar to that of healthy $M$. gregalis nests, and subculturing suggested the presence of three morphologically-distinct types of yeasts. 
Table 1. Relative growth (average of triplicates) and odor of microflora on differential media. Determination of colony type was based on colony morphology and growth was scored within individual plates ("+" indicates relative number of colonies; "-" no colony growth and/or no odor; "S" a sweet odor, similar to that of the Mallos gregalis nest; " $\mathrm{R}$ " a rancid odor; and " $\mathrm{nt}$ " indicates not tested).

\begin{tabular}{|c|c|c|c|c|}
\hline \multirow[t]{2}{*}{ SOURCE } & \multicolumn{4}{|c|}{ SABORAUD } \\
\hline & Yeast & Mold & Bacteria & Odor \\
\hline Flies fed upon by $M$. gregalis & + & + & - & $\mathbf{S}$ \\
\hline Non-fed-upon flies & + & ++ & + & $\mathbf{R}$ \\
\hline Female $M$. gregalis & - & +++ & ++ & $\mathbf{R}$ \\
\hline Clean silk from $M$. gregalis nests & - & ++ & + & $\mathbf{R}$ \\
\hline Fly food (unsoiled) & - & ++ & + & $\mathbf{R}$ \\
\hline Fly food (soiled from fly cage) & - & +++ & ++ & $\mathbf{R}$ \\
\hline $\begin{array}{l}\text { Flies fed upon by other species } \\
\text { of spiders }\end{array}$ & - & +++ & ++ & $\mathbf{R}$ \\
\hline SOURCE & \multicolumn{4}{|c|}{ PYG } \\
\hline Flies fed upon by $M$. gregalis & +++ & + & - & $\mathrm{S}$ \\
\hline Non-fed-upon flies & ++ & ++ & - & $\mathbf{S}$ \\
\hline Female $M$. gregalis & - & +++ & ++ & $\mathbf{R}$ \\
\hline Clean silk from $M$. gregalis nests & - & ++ & + & $\mathbf{R}$ \\
\hline Fly food (unsoiled) & - & ++ & + & $\mathbf{R}$ \\
\hline Fly food (soiled from fly cage) & - & +++ & + & $\mathbf{R}$ \\
\hline $\begin{array}{l}\text { Flies fed upon by other species } \\
\text { of spiders }\end{array}$ & nt & nt & nt & nt \\
\hline SOURCE & \multicolumn{4}{|c|}{ TSA } \\
\hline Flies fed upon by $M$. gregalis & +++ & + & + & $\mathbf{S}$ \\
\hline Non-fed-upon flies & + & + & +++ & $\mathbf{R}$ \\
\hline Female $M$. gregalis & nt & nt & nt & nt \\
\hline Clean silk from $M$. gregalis nests & $\mathrm{nt}$ & nt & nt & $\mathrm{nt}$ \\
\hline Fly food (unsoiled) & nt & nt & nt & nt \\
\hline Fly food (soiled from fly cage) & nt & nt & nt & nt \\
\hline $\begin{array}{l}\text { Flies fed upon by other species } \\
\text { of spiders }\end{array}$ & nt & $\mathrm{nt}$ & nt & nt \\
\hline
\end{tabular}

Non-fed-upon flies cultured on TSA agar had a rancid odor due to the large number of bacterial and non-yeast fungal colonies. However, non-fed-upon fly homogenates on differential media (PYG and Saboraud) indicate that the yeasts are normally present on the flies before feeding by $M$. gregalis. Other potential sources of microbiota (fly food, adult female $M$. gregalis, and silk) did not contain the yeasts. 
We have examined the microbiota associated with the fieldcollected nests of $M$. gregalis and obtained identical results, indicating that the odor and its source is similar in field and laboratory populations. This suggests that feeding by $M$. gregalis alters conditions within fly carcasses so that the usual competitive growth advantage of bacteria is shifted toward the yeasts and/or bacterial growth is inhibited. Homogenates of flies fed upon by other spider species did not show evidence of such a growth advantage for the yeasts (Saboraud media).

Nest material with fly carcasses was attractive to flies while silk alone showed no such attraction (Fig. 2). Cultures of yeasts derived from the fed-upon flies were similarly attractive to flies while cultures from non-fed-upon flies showed no attraction. In addition, both the nest material with prey and yeast stimulus attracted more flies than either the non-fed-upon microflora or clean silk alone (Chi Square and Wilcoxon tests; $p<0.01$ ). The higher attractiveness found in controls for nest material and fed-upon flies as compared to non-fed-upon flies and clean silk could be accounted by the generally higher activity of the flies in the presence of the yeasts.

\section{Discussion}

The present research suggests that $M$. gregalis attract their prey by using odors based on a symbiotic relationship between spiders and yeasts. Although other social arthropods, such as the fungusgrowing ants, beetles and termites make use of yeasts and/or fungus, the function is one of "farming" a crop for food (Wilson 1971). To our knowledge, this is the first example of any organism using microflora as a means of attracting prey through an odor. Under natural conditions, visual cues of the fly carcasses on the web may provide additional attraction (Jackson 1980).

Most discussions on evolution of sociality in spiders emphasize the maternal route in which the young remain with the mother for an extended period of time. Among the Eresidae and Theridiidae, for example, a progression from one level of aggregation (parents and offspring) to another (several generations present on the web) is well documented (Buskirk, 1981). Recent arguments suggest that for $M$. gregalis, unrelated individuals may have gained a foraging advantage by collective nest construction (Fritz, 1984; Tietjen, 1986). 


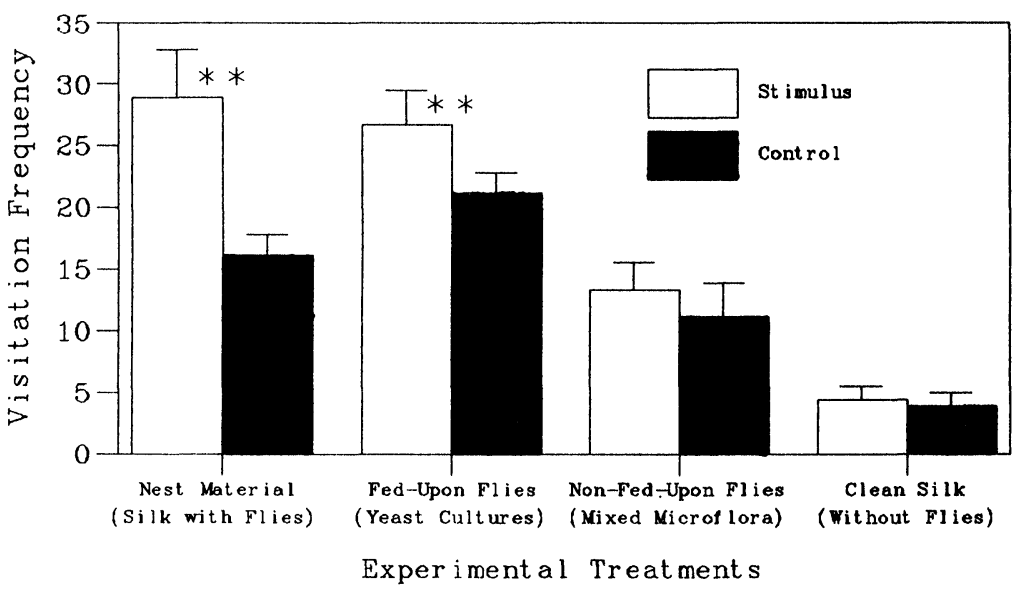

Fig. 2. Mean visitation of grouped flies to paired experimental odors. For tests using Mallos gregalis silk (with and without flies), the silk provided the experimental odor while empty covered dishes were controls. Those tests using microorganisms as an odor source used sterile agar as the control. Asterisks indicate a significant difference in visitation frequencies within a test (Chi Square and Wilcoxon Tests; $p<.01$ ).

Those individuals with increased tolerance of neighbors would have a greater concentration of fly carcasses (and their associated yeasts) to attract prey. Further increases in interspider tolerance and eventual construction of a communal nest would provide additional concentration of prey attractants. The use of microbiota is not without disadvantages, however, since a large prey input may not be adequately fed upon by the spiders resulting in a shift to bacterial growth and an ammonia-based odor. Under such conditions the colony must abandon the nest and start construction anew.

\section{ACKNOWLEDGMENTS}

This work was supported, in part, by a research grant from the National Science Foundation (BNS 79-10186 to W. J. T.). Specimens were collected during field expeditions funded by the National Geographic Society and the American Philosophical Society (grants to G. W. U.). We thank C. A. Meininger and M. J. Benton for assistance in the field, D. Fritz and M. Hodge for assistance in rearing spider colonies, M. Kaufman for SEM photography and preparation. 


\section{Literature Cited}

ALCock, J.

1984. Animal Behavior: An Evolutionary Approach. Sinauer Associates, Inc., Publ., Mass. p. 282.

BURGESS, J. W.

1978. Social behavior in group-living spider species. Symp. Zool. Soc. London 42: 69-78.

BURGESS, J. W.

1979. The spider species Mallos gregalis: Behavioral adaptations for living in Mexico. PhD Dissertation. North Carolina State Univ. Raleigh, N.C.

Buskirk, R. E.

1981. Sociality in arachnida. In H. R. Hermann, ed. Social Insects, Vol. 2. Academic Press, London, pp 282-367.

DigueT, $L$.

1909a. Sur l'aranignee mosquero. C. R. Acad. Sci. Paris, 148: 735-736.

DigueT, L.

1909b. Le mosquero; nid d'araignee employe a Mexique comme pie'ge a' mouches. Naturaliste, Paris, 31: 283-285.

FRITZ, D.

1984. Parental care, juvenile development, and nestmate recognition in Mallos gregalis Amer. Arachnol. 30: 11.

JACKSON, R. R.

1977. Comparative studies of Dictyna and Mallos (Araneae, Dictynidae). III. Prey and predatory behavior. Psyche 84: 267-280.

JACKSON, R. R.

1980. Does the web of the social spider Mallos gregalis (Araneae, Dictynidae), attract flies? Bull. Br. Arachnol. Soc. 5: 91-94.

TIETJEN, W. J. AND J. S. RovNeR

1982. Chemical communication in lycosids and other spiders. In P. N. Witt and J. S. Rovner, eds. Spider Communication: Mechanisms and Ecological Significance. Princeton Univ. Press, Princeton, N.J. pp. 249-280.

TietJen, W. J.

1986. Social spider webs with special reference to the web of Mallos gregalis. In W. Shear, ed. Spiders: Webs, Behavior, and Evolution. Stanford Univ. Press, Stanford. pp. 172-206.

UETZ, G. W.

1983. Sociable spiders. Nat. Hist. 92: 62-69.

WILSON, E. O.

1971. The Insect Societies. Harvard Univ. Press, Cambridge. pp 41, 118, 127-128. 

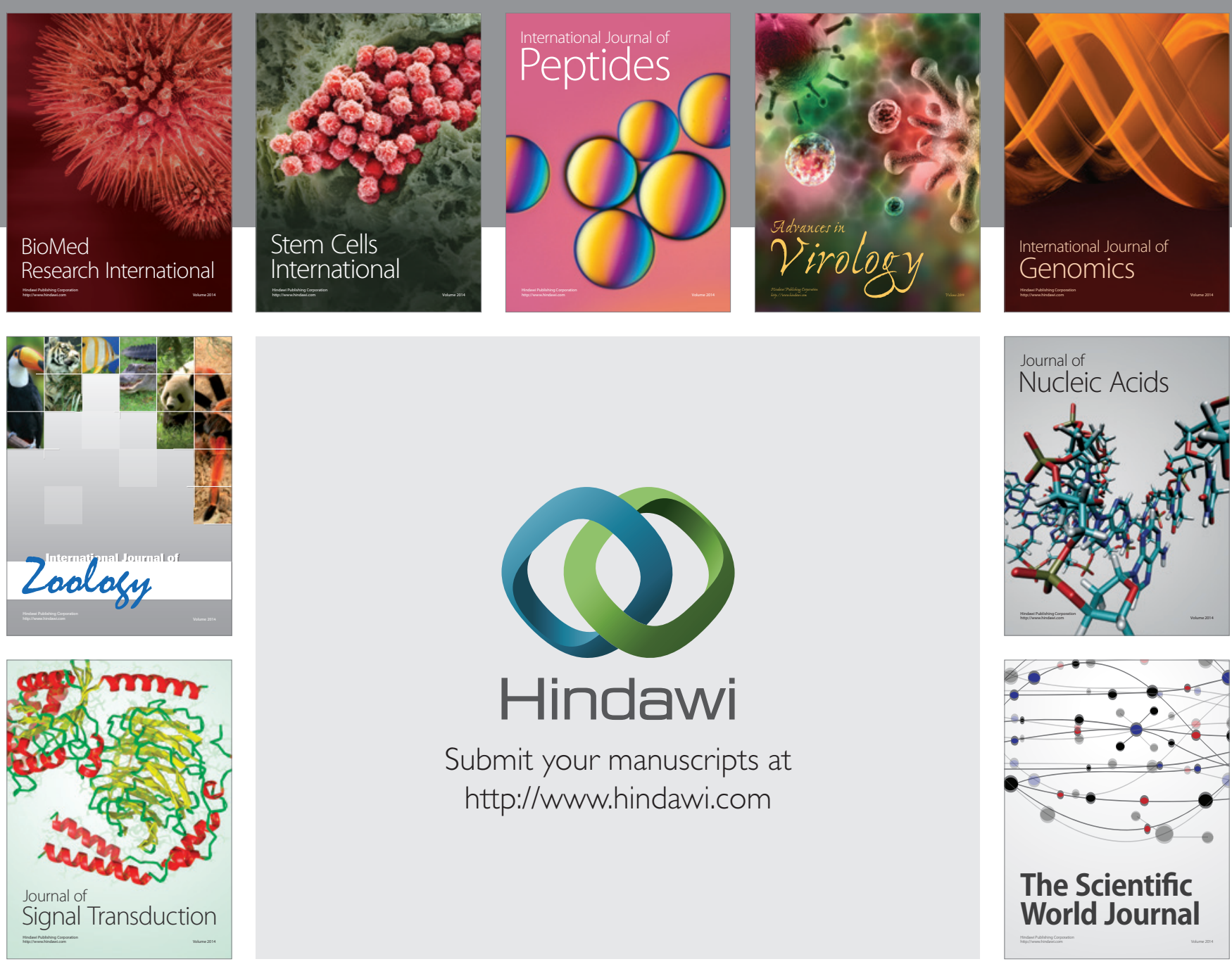

Submit your manuscripts at

http://www.hindawi.com
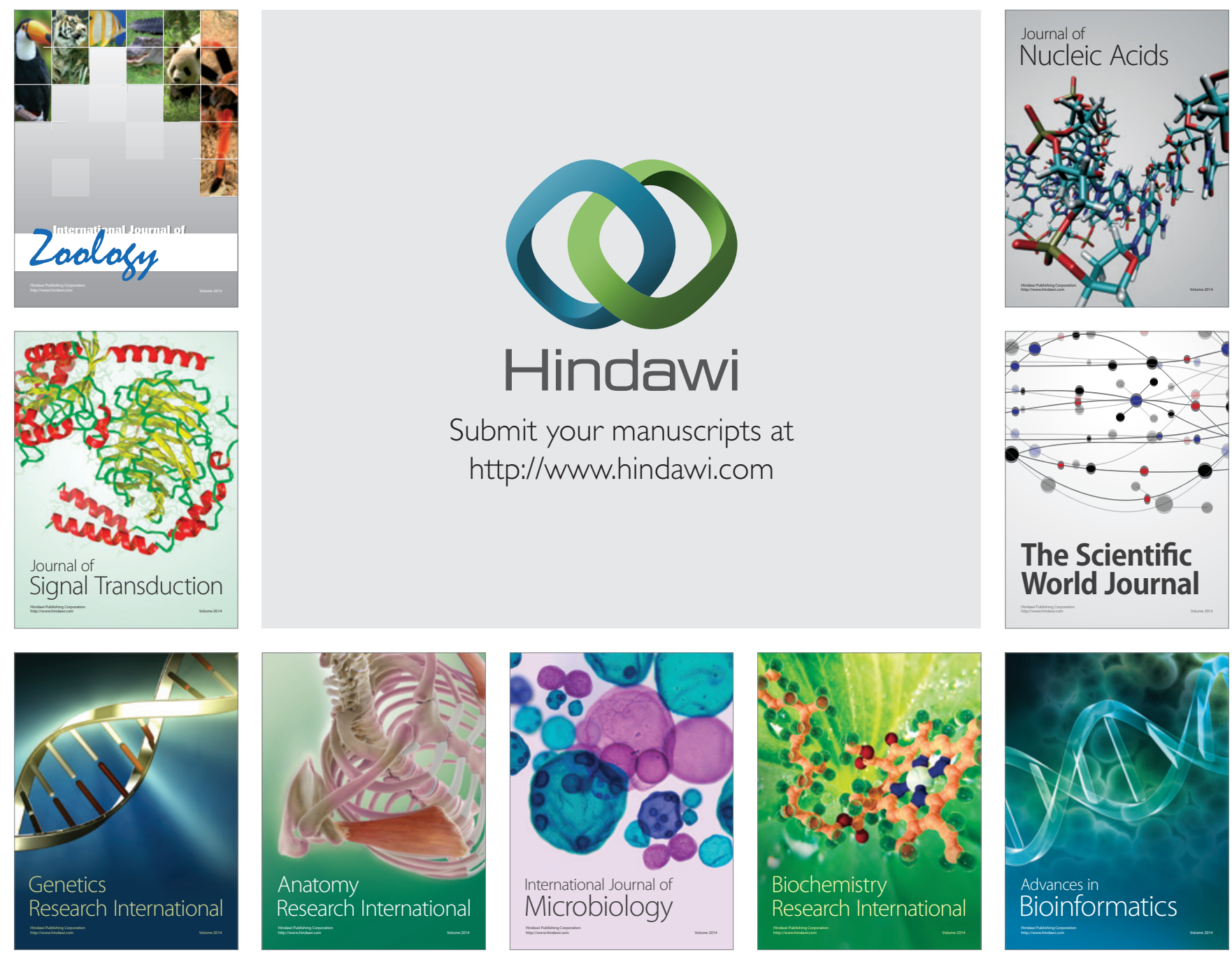

The Scientific World Journal
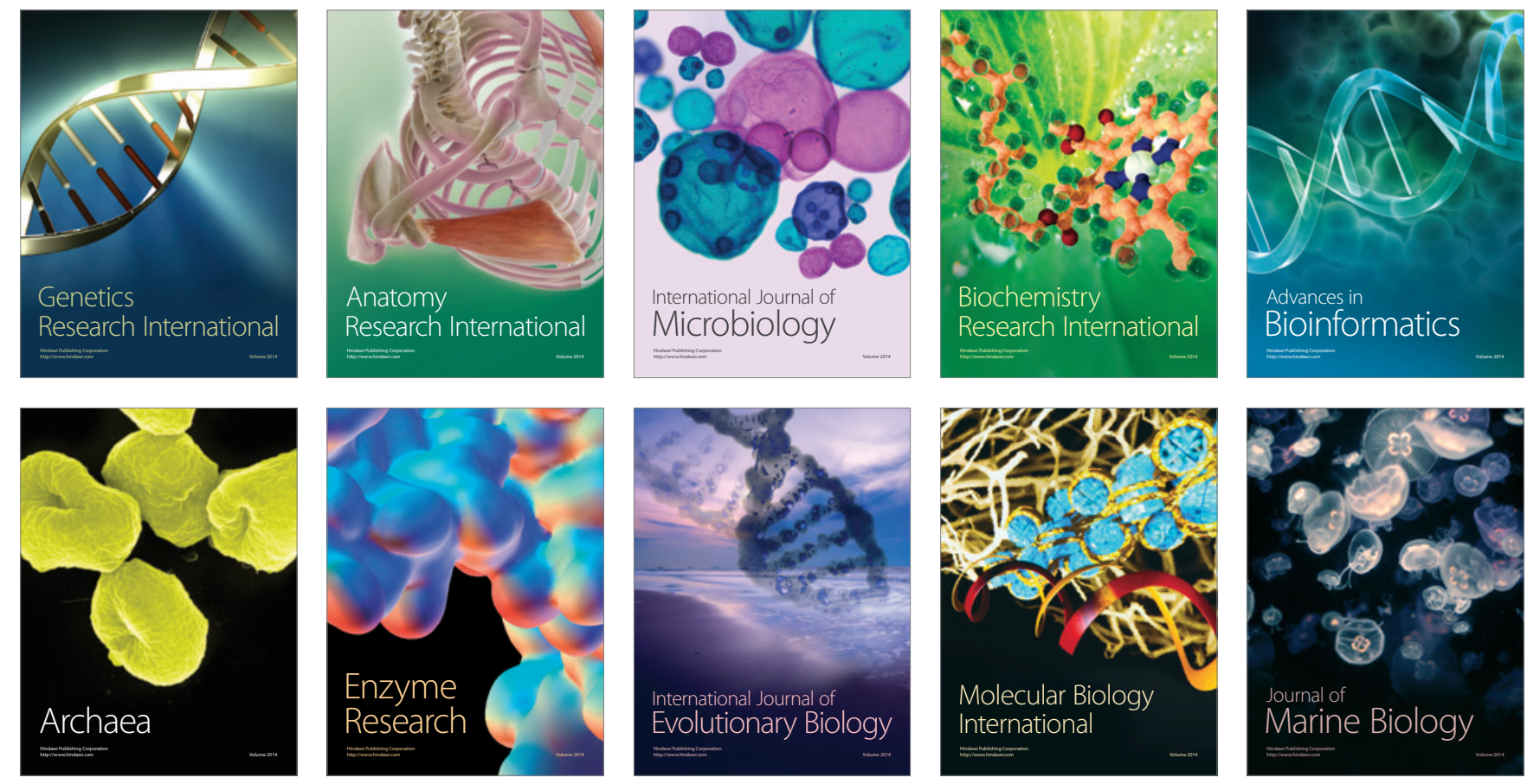